\title{
La expedición a Veracruz y de defensa de San Juan de Ulúa (1819-1825)
}

\author{
MANUEL ESCALONA JiMÉNEZ
}

\begin{abstract}
RESUMEN ABSTRACT
En 1819 una expedición militar al mando del teniente general Manuel Cagigal partió de Cádiz hacia La Habana. En 1821 el cuerpo expedicionario, compuesto de unos 200 hombres, ocupó Veracruz, pero pronto se vio obligado a replegarse a la isla de San Juan de Ulúa, donde consiguió resistir hasta 1825, a pesar de estar sometido al severo bloqueo de las fuerzas independentistas mexicanas y combatir en las condiciones más precarias, de tal modo que este episodio militar se ganó la admiración general.

In 1819, a military expedition, under the command of Lieutenant General Manuel Cagigal, sailed from Cádiz bound to La Habana. In 1821 , the army corps, around 200 soldiers, got hold of Veracruz, but was soon obliged to retire to the island of San Juan de Ulua, where they managed to resist until 1825, in spite of the blockade by the Mexican independentist Mexican force and the arduous circumstances of the fight to the extent of getting a general admiration.
\end{abstract}

Era costumbre que ante momentos de apuros debidos al ataque de otras potencias interesadas en la posesión de las provincias americanas, las unidades del ejército regular español se trasladasen a aquellas tierras para colaborar en su defensa. Pero fue sobre todo a partir de los movimientos de emancipación cuando las expediciones cobraron un mayor auge, más cuando el gobierno español tuvo plena conciencia de las consecuencias que entrañaría la pérdida definitiva de Costa Firme ${ }^{1}$.

Para profundizar sobre el empleo y situación de las unidades militares en América, tanto de las de Dotación como de las de Refuerzo, se pueden consultar las siguientes obras: KUETHE, 
La primera gran expedición que se organizó en 1815 para impedir la emancipación fue la denominada «Expedición Pacificadora de Costa Firme" a cargo del general Pablo Morillo ?. Los resultados finales fueron negativos, pues a pesar de los éxitos en los enfrentamientos iniciales la falta de aclimatación de las tropas y las largas campañas debido a lo extenso de los territorios a recuperar trajeron como consecuencia el retraimiento de la acción ofensiva, hasta que la derrota final se materializase en 1824 en la batalla de Ayacucho ${ }^{3}$.

Nueva España fue una de las provincias donde se desencadenó en fecha temprana el movimiento de emancipación (gracias a la cercanía y consiguiente apoyo de la nueva potencia americana, Estados Unidos). La declaración de independencia suponía la desarticulación del sistema económico americano y la consiguiente pérdida de unos ingresos vitales, especialmente los "situados" remitidos a Cuba y demás islas españolas, que hasta entonces habian permitido mantener el sistema administrativo y las numerosas tropas allí existentes ${ }^{4}$.

Ante esta difícil situación, la Monarquía determinó enviar en 1819 otro cuerpo expedicionario, que procedente de la Península marchara hacia Cuba para formar junto a las tropas de la isla un ejército que bajo la dirección del Capitán General ocupara Veracruz para ser utilizada posteriormente por un fuerza mayor y así proceder a completar la reconquista de Nueva España. La denominada Expedición a Ultramar al mando del conde de la Bisbal se formó en Cádiz. Las fuerza reunidas se organizaron a su vez en dos agrupaciones. Una era la "Expedición Grande", que tenía primero como destino Veracruz y luego el Río de la Plata, pero que no partió al final, como se sabe, por el pronunciamiento de Riego en Las Cabezas de San Juan. La otra era la «Expedición Chica», que bajo el mando del teniente general Manuel Cagigal debía llevar a Cuba una fuerza de tres mil hombres compuesta por los batallones de infantería de Málaga, Cataluña y Tarragona y formar alli el mencionado ejército con destino a Veracruz.

\footnotetext{
Allan James, Cuba 1753-1815. Crown, military and society. Knoxville, 1986, y MARCHENA FERNANDEZ, Juan: Oficiales y soldados en el Ejército de América. Sevilla, 1983.

2 Para un mayor conocimiento del tema están las obras de Rodriguez VILLA, Antonio, El Theniente General don Pablo Morillo, primer Conde de Cartagena y Marqués de la Puerta (1778-1837). Madrid, 1920, y de Arámbari, Francisco Xavier, Hechos del General Pabio Morillo. Murcia, 1971

3 En el libro de CÉSPEDES del CASTILLO, Guillermo, La independencia hispanoamericana. Madrid, 1988, se hace un análisis detallado de las campañas militares.

4 Un estudio completo del desarrollo del proceso de independencia de Nueva España se puede realizar con las obras de $\mathrm{LYNCH}$, John, Las revoluciones hispanoamericanas. Barcelona, 1976, y ORTíz DE LA TABI.A, Javier, Comercio Exterior deVeracriz: 1778-1821. Crisis de dependencia. Sevilla, 1978.
} 
La expedición, que partió de Cádiz el 14 de julio de 1819, desembarcó en La Habana el 30 de agosto, siendo alojadas las tropas entre los castillos de la Cabaña y del Príncipe ${ }^{5}$. Como no venían aclimatados y las condiciones de salubridad de sus alojamientos eran pésimas, los soldados comenzaron a enfermar de manera alarmante, falleciendo muchos de ellos, de forma que en caso de no ponerse remedio a aquella situación la rápida disminución de los hombres en las unidades podía dar al traste con la expedición. La solución fue bajar el mayor número de soldados a la ciudad y villas de alrededor y alojarlos sobre todo en los conventos, donde aunque seguían escasos de espacio mejoraron las condiciones sanitarias ${ }^{6}$.

En Cuba se inició la organización de la expedición a Veracruz en medio de numerosas dificultades, pues aunque se contaba con el número de hombres previsto había otras carencias, sobre todo la falta de buques para efectuar el transporte y de fondos para avituallar las tropas. Así, la fecha de partida se fue retrasando y las unidades llegadas de la Península, o sea los batallones de Málaga, Tarragona y Cataluña, tuvieron que ser empleadas mientras tanto en otras actividades militares, lo cual permitió al Capitán General utilizar interinamente a un buen número de hombres para cubrir los innumerables destacamentos esparcidos por las distintas fortalezas y villas de la isla.

Desde sus cuarteles en la capital los soldados se desplazaban en largas marchas a pie por caminos intransitables, sobre todo durante los períodos de lluvia o intenso calor, hacia los castillos de San Severino, Vigía o Morrillo en Matanzas y Jagua en Trinidad o al torreón del Jaru$\mathrm{co}$, entre otros, llegando en condiciones lamentables. Esta circunstancia, unida al servicio continuado por la escasez de hombres que componían los destacamentos, lo insano de los alojamientos y la deficiente alimentación a pesar de los desvelos de las autoridades militares de las jurisdicciones, hacía que la tropa enfermera con rapidez. El destacamento menos apetecible era (hasta su cesión en 1823 a Estados Unidos) el existente en San Agustín de la Florida, compuesto por piquetes de todas las unidades ubicadas en La Habana, donde el relevo se realizaba cuando había algún buque disponible y donde sobre todo, se padecía una carencia casi total de los productos básicos para la subsistencia, debiendo los soldados dedicarse a la pesca para poder comer algún alimento fresco ${ }^{7}$.

Archivo General de Indias, Papeles de Cuba, legajo 1942.

AGI., Papeles de Cuba, legajo 1983.

AGI., Papeles de Cuba, legajo 1942. 
Para completar las frecuentes bajas de las unidades expedicionarias, pues a los enfermos y fallecidos había que sumarles los desertores, desaparecidos y condenados a presidio, cantidad nada despreciable, arribaban con cierta asiduidad convoyes con tropa reclutada en la Península. Los nuevos soldados llegaban a la isla en condiciones penosas, pues aparte de los fallecidos durante la travesía, que no eran pocos, los supervivientes venian en parte enfermos por los avatares del viaje, dado que muchos era la primera vez que navegaban, y sobre todo por la falta de aclimatación, y la mayoría casi desnudos, pues se esperaba que fueran provistos de vestuario al llegar a su unidad, aunque era frecuente que por falta de tiempo fueran embarcados para los destacamentos, sobre todo para San Juan de Ulúa, en el mismo estado de desnudez en que habían llegado a la isla. A pesar de ello, la intención del Capitán General era que, una vez en La Habana, pasaran al castillo del Príncipe para descansar y adaptarse a las condiciones ambientales de la isla ${ }^{8}$.

Por fin tras estos avatares pudo organizarse la esperada expedición, para dar cumplimiento a la Real Orden recibida por el Capitán General Mahy, por la que debía socorrer a Veracruz con mil hombres de infantería y cien artilleros. La fuerza se denominó «Cuerpo Expedicionario de la Isla de Cuba", siendo nombrado comandante de la misma el mariscal de campo Juan Moscoso, jefe del Estado Mayor de La Habana. Éste, no muy conforme con el nombramiento, urgió al Capitán General a reunir a la junta de generales antes de acometer la aventura para pedir su aprobación, a lo que respondió Mahy que bastaba su autoridad para tomar aquella decisión y que por lo tanto le comunicara si pensaba cumplir la orden, pues en caso contrario nombraría jefe de la misma al brigadier Juan Rodríguez de la Torre, como al final ocurrió.

Esta primera expedición era en realidad un destacamento avanzado compuesto por cuatro compañías, la primera de 105 hombres del ejército regular (formada por piquetes de los regimientos de La Habana y La Luisiana y los batallones de Málaga, Cataluña y Tarragona), la segunda de 75 hombres del batallón de Pardos de La Habana, la tercera con la misma fuerza del batallón de Morenos, también de la capital, y la última, de 105 soldados veteranos y voluntarios sueltos.

Aunque la fuerza estaba lista para salir en mayo de 1821, no to hizo hasta el 7 de agosto del mismo año, partiendo del puerto de La Habana para llegar, después de once días de navegación y empujados por una

8 AGI., Papeles de Cuba, legajo 1983. 
tormenta, al puerto de Campeche, donde tras repostar agua y víveres continuaron el viaje hacia Veracruz, en cuyo puerto atracaron el día 25 del mismo mes, desplegando la tropa para la defensa de la ciudad ${ }^{9}$.

Pocos días después de la primera partida, se organizó una segunda expedición de refuerzo, con 299 soldados y 11 oficiales de las mismas unidades que la anterior, por lo que una vez llegados a Veracruz la fuerza aumentó a unos 700 hombres, con lo cual se creía tener segura la defensa de la ciudad hasta la venida del grueso del cuerpo expedicionario ${ }^{10}$.

La tercera expedición estaba compuesta por 834 soldados de infantería (prácticamente el batallón de Cataluña reforzado por el de Málaga), además de 44 oficiales, 7 mujeres, 11 hijos y 2 esclavos de los oficiales y de la tropa y 100 artilleros. Nuevamente requirió el Capitán General a Moscoso para que se hiciera cargo de ella, advirtiéndole de que en caso contrario sería relevado de todo cargo y sumariado. Moscoso estaba totalmente convencido del fracaso del cuerpo expedicionario, de acuerdo con las varias razones que expuso. Según la información del capitán del navío "Asia", llegado a La Habana procedente de Veracruz, los independentistas se hallaban en las inmediaciones de aquella ciudad con la fuerza de un batallón, más otro que se hallaba en marcha para reforzarle y una división que había partido de Santa Fe para sitiar y después ocupar la plaza. Según la opinión del citado capitán, sólo se debería socorrer el castillo de San Juan de Ulúa con 300 ó 400 hombres de confianza, bien abastecidos de víveres y combustible y que pudieran ser relevados cada tres meses, a no ser que el Capitán General pudiera mandar una expedición en toda regla para recuperar la provincia.

Continuaba Moscoso la justificación a su negativa a marchar a Veracruz, manifestando que de los soldados trasladados anteriormente a aquella ciudad, muchos habian desertado e incluso otros se habian pasado al enemigo, sin contar los que habían desaparecido en La Habana antes de partir. Además su fuerza debía ser de 1200 hombres, artilleros aparte, y sólo la componían 834 , a lo que replicó Mahy que no tenía más hombres disponibles, pero que había pedido al Rey un regimiento para reforzar la isla y había sido informado de que el de Barcelona con 1000 hombres se hallaba en Cádiz presto para embarcar ${ }^{11}$.

Pero Moscoso no se daba por vencido, adelantando unas previsiones de lo que podía ocurrir en aquella aventura. Calculaba la guarnición española

AGI., Papeles de Cuba, legajo 1988

AGl., Papeles de Cuba, legajo 1983.

AGI., Papeles de Cuba, legajo 2115 
en 800 hombres, de los que la cuarta parte enfermaría, mientras el servicio de guerra ocuparía a otros 300 , por lo que sólo la mitad podría estar de descanso, sacando la conclusión de que era una temeridad defender la ciudad con tan poca fuerza. En su opinión, España no debería embarcarse en esa guerra sin tener la seguridad de su éxito, pues aquel esfuerzo sólo valdría para defender el castillo de San Juan de Ulúa, y que aun así terminaría por caer en poder de los insurgentes. La expedición de la Península no le infundía ninguna confianza, pues según su información las embarcaciones para el transporte no estaban reunidas y carecían de viveres y marineros. Incluso si se llevaba a efecto, a lo sumo valdría para conservar el castillo hasta que los sucesos políticos decidieran su situación.

Al Capitán General le pareció muy razonable esta exposición, pero la Real Orden le obligaba a enviar aquel refuerzo al gobernador de Veracruz, el mariscal de campo José Dávila, pues en caso contrario sería responsable de la pérdida de la plaza. De este modo, urgió nuevamente a Moscoso a pronunciarse sobre si definitivamente se haría cargo de la expedición, a lo que el mariscal respondió que carecía de autoridad para nombrarle. Pese a tales enfrentamientos, parece ser que Moscoso debió pensárselo mejor, ya que finalmente el 21 de octubre de 1821 partió de La Habana al mando de las tropas con destino a Veracruz ${ }^{12}$.

La buena organización inicial de la defensa de la ciudad se fue deteriorando al poco tiempo, sobre todo por el aumento del númerc de enfermos en la tropa y por la presión de los disidentes, pese a que, según De la Torre, "se encontraban a medio tiro de pistola, pero eran nulos y sin organización y ellos estaban preparando la defensa". No debieron ser así las cosas pues en efecto, en la noche del 26 de octubre de 1821 las fuerzas realistas hubieron de retirarse al castillo de San Juan de Ulúa, quedando un piquete bajo su mando para cubrir la salida de las tropas ${ }^{13}$.

Cuando llegó Moscoso con su expedición se encontró Veracruz ocupada por los independentistas, por lo que tuvo que desembarcar las fuerzas en el castillo de Ulúa. Una vez tomado el mando del mismo, procedió inmediatamente a solicitar un refuerzo de 400 hombres más 50 artilleros. Pero la idea de permanecer en aquella fortaleza no le debía agradar mucho, por lo que hizo una nueva exposición de la situación al Capitán General, alegando que el castillo, rodeado de agua por todas partes y a un tiro largo de cañón, sólo precisaba salud en los soldados,

\footnotetext{
AGI., Papeles de Cuba, legajo 1988.

AGI. Papeles de Cuba, legajo 1988.
} 
víveres y municiones, por lo que su misión allí había terminado, y pedía su relevo y posterior traslado a Cuba. Mahy atendió su petición, pues fue sustituido por el brigadier Francisco Lemaur ${ }^{14}$.

El castillo de San Juan de Ulúa era una impresionante fortaleza construida en una pequeña isla en forma de rada, toda fortificada, de unos ochocientos metros de longitud por doscientos de anchura, a menos de dos mil metros del puerto de Veracruz. Igualmente admirable era su defensa artillera, con 132 bocas de fuego, entre cañones de todos los calibres y morteros, y aunque el estado de las cureñas, pólvoras y municiones dejaba mucho que desear, el respeto que le ofrecía al enemigo era tal que no se atrevía a acercarse a él, quedándole el asedio como única posibilidad de conseguir la victoria ${ }^{15}$. En su interior había alojamiento, según su gobernador, para 1670 personas incluido pabellones para 122 oficiales y sus familiares, todos protegidos de los disparos de la artillería. Contenía también una prisión militar, con más de 100 presos de media empleados en los trabajos de fortificación ${ }^{16}$.

La ruptura de hostilidades contra Ulúa se produjo a partir de mayo de 1822, cuando fue proclamado emperador el coronel Itúrbide, con el nombre de Agustín I. En septiembre, los mejicanos habian tomado totalmente Veracruz, pues los españoles que seguían resistiendo en los edificios de la diputación y el ayuntamiento, tuvieron finalmente que abandonarlos y replegarse al castillo. Acto seguido comenzaron los insurgentes los trabajos para preparar el asedio a la fortaleza, no viendo el gobernador Lemaur otra solución que iniciar las acciones de guerra contra ellos, con un bombardeo sobre el puerto una vez que los buques españoles se dieron a la vela ${ }^{17}$.

La intención del Capitán General de Cuba era relevar a las unidades destacadas en Ulúa cada cuatro meses para mantener alta la moral y evitar las enfermedades, frecuentes en aquel lugar insano donde la tropa estaba sometida a un servicio casi continuo. Para ello eran necesario mantener el contacto con la isla, de donde debían venir las tropas de refuerzo, los víveres y los suministros para resistir el asedio. De momento no parecía existir ninguna dificultad, ya que los insurgentes no dominaban el mar. Sin embargo, había que contar con el inconveniente para el cumplimiento del plazo previsto para el relevo de la posible falta de buques de transporte 0 de tropas de refresco, como en realidad ocurrió.

\footnotetext{
14 Ibidem.

15 Lerdo de Tejada, Miguel, La fortaleza de San Juan de Uhia. Tacubaya,1961.

AGI., Papeles de Cuba, legajo 2115.

AGI., Papeles de Cuba, legajo 2115.
} 
Hasta el 24 de diciembre de 1822 no partió de La Habana el primer destacamento de relevo, compuesto por 436 hombres de infantería procedente la mayoría del batallón de Málaga con 354 soldados y 8 oficiales, siendo los 74 restantes del batallón de Tarragona. Durante la travesía naufragó cerca de Tabasco uno de los buques de transporte de tropas, el "Todos los Santos", cayendo en manos de los insurgentes tanto la tripulación como los pasajeros, aunque gracias a las negociaciones del Capitán General de Nueva España fueron puestos en libertad, llegando la expedición a Ulúa entre el 15 y 18 del mes siguiente ${ }^{18}$.

La población del castillo estaba ahora compuesta por algo más de 1300 personas de las tropas regulares de los batallones de infantería de Cataluña, Tarragona y Málaga, además de los milicianos pardos y morenos, los artilleros, las guarniciones del castillo y la de Veracruz allí refugiada, los marineros y más de 100 presidiarios.

El 12 de marzo de 1823 se hizo a la mar el siguiente relevo, constituido por una fuerza similar a la anterior de los batallones de Tarragona, Cataluña y Málaga. La mayor parte de la tropa estaba formada por reclutas recién llegados a La Habana desde la Península, por lo que no había dado tiempo a confeccionarles el vestuario y el calzado y venían casi desnudos; por si fuera poco, un fuerte temporal que les azotó durante ocho días en la travesía inundó los buques y a punto estuvieron de perder la vida. EI gobernador Lemaur pidió dinero al Capitán General para poder vestir a la tropa (en el castillo, a pesar de su aislamiento, estaban instalados todo tipo de comerciantes ocupados en estos menesteres, por lo menos al principio del asedio), pero aunque la necesidad era evidente, aquel se negó alegando la falta de fondos ${ }^{19}$.

Como en agosto de 1823 pasaba ya un mes del tiempo estipulado para el relevo, Lemaur quiso enviar la tercera parte del destacamento de Ulúa a La Habana sin esperar la llegada del próximo, debido al riesgo que suponía este retraso, sobre todo en el personal del batallón de Málaga a las órdenes del teniente coronel José Roca Sancti Petri. En efecto, el día 25 habia llegado desde Cataluña la corbeta americana "Victoria" y desde Cádiz el bergantín español "Firme» con la noticia de la retirada del gobierno español a esta ciudad, bloqueada por la escuadra y las tropas francesas. Por la noche comenzaron los soldados a cantar varias coplas con estudiada exaltación, dando al final de ellas vivas a Riego y a la unión

8 Ibidem

19 AGi., Papeles de Cuba, legajo 1983. 
entre los españoles y mueras a los serviles, aumentándose el tono de voz durante la lista de retreta. Además había oído Lemaur que se estaban pasando consignas entre ellos para no obedecer a los oficiales en todo aquello que fuera contrario al sistema constitucional $y$, para en caso de restauración del absolutismo, tomar el dinero depositado en le castillo (varios millones de pesos) y desertar a los Estados Unidos. Se convocó la junta de oficiales, donde se decidió enviar un tercio del destacamento a La Habana, pero desgraciadamente no había buques disponibles. En principio sólo pudieron embarcarse 150 hombres (entre una goleta de guerra y un bergantín), y 50 más en enero de 1824, no llegando el relevo de los 200 hasta agosto de ese año ${ }^{20}$.

En mayo de 1824 se iban perdiendo las esperanzas en el relevo de las tropas. Además estaban escaseando los suministros y viveres tras cinco meses sin comunicación, careciendo los soldados de calzado para hacer los servicios ahora que se acercaban las lluvias. La falta de alimentos frescos estaba causando estragos, sobre todo el escorbuto y las fiebres amarillas, llegando a pensar los soldados que se habían olvidados de ellos. Los ánimos estaban tan exaltados, que el 18 de ese mes, para responder al apresamiento por parte de los insurgentes de las barcas del castillo dedicadas a la pesca como única opción de comer algo fresco, se abrió un vivo fuego sobre el puerto de Veracruz, lo cual levantó la moral de los soldados y de momento calmó la situación.

Como el relevo seguía sin llegar, el teniente coronel Roca, gobernador accidental del castillo por enfermedad de Lemaur, envió un comunicado al Capitán General alegando que "el gobierno debía cumplir los cuatro meses que se había señalado como sagrado para el cumplimiento del tiempo, y lo reclamaba imperiosamente por la situación de estos beneméritos defensores, arrostrados por 16 meses el confinamiento y las privaciones, los trabajos continuos de fuego y los rigores de un bloqueo, el escorbuto, las calenturas estacionales, los ataques enemigos y la continuación de comer sólo alimentos salados, que era para tenerlo en consideración. El Batallón de Málaga tenía más de 50 enfermos de peligro, 10 fallecidos, y la tropa sin calzado ni vestuario, pues tenía más de 8 años de servicio".

La situación mejoró algo con la llegada desde Nueva Orleáns (convertida ahora en su principal fuente de abastecimiento) de medicinas y algunos alimentos frescos, de modo que si el número de enfermos no disminuyó demasiado, sí remitió la gravedad de sus dolencias, llegando a

\footnotetext{
20 AGI., Papeles de Cuba, legajo 2115.
} 
detenerse el progreso del escorbuto, además de que se pudieron calzar 100 hombres con los zapatos suministrados ${ }^{21}$.

Hasta julio de 1824 no salió otra expedición para Ulúa, compuesta de 227 hombres de los batallones de Cataluña y Tarragona. Una vez desembarcados en el castillo, regresó el convoy a La Habana transportando solamente a los enfermos y convalescientes que habían logrado salvarse de los rigores del escorbuto. Pero no llegaron los haberes de la tropa y de los oficiales, por lo que Roca, para evitar males mayores, se vio obligado a pedir dinero prestado a los comerciantes instalados en la fortaleza ${ }^{22}$.

A partir de noviembre la situación empeoró nuevamente a causa del escorbuto. Conocedores de esta situación, los independentistas intensificaron el asedio al castillo, no permitiendo el abastecimiento de viveres desde La Habana y Nueva Orleáns, por lo que el nuevo gobernador de la fortaleza, el brigadier José Callava, tuvo que reducir la ración de pan a la mitad. Los soldados estaban también en tal estado de desnudez que se tomó la medida de dar los zapatos de los enfermos de mayor gravedad (pensándose que ya no harían más uso de ellos) a los sanos que los necesitaban para realizar los servicios en la guarnición ${ }^{23}$.

En enero de 1825 partió desde La Habana una expedición de 300 hombres de los batallones de Cataluña y Tarragona, más 116 de los batallones de Pardos y Morenos, acompañados por el brigadier José Coppinger, para relevar a José Callava como gobernador de la fortaleza, ya que se encontraba enfermo de escorbuto. En su regreso a Cuba transportó a 542 hombres, no quedando por lo tanto ya ninguna tropa por relevar. Esta fue la última fuerza que desembarcó en Ulúa, pues la siguiente expedición, que partió en octubre de 1825, al llegar el convoy cerca del castillo, dio media vuelta ante la presencia de una escuadrilla de guerra enemiga ${ }^{24}$. A partir de entonces los insurgentes dejaron salir los buques que transportaban a las tropas o a los enfermos, pero no permitieron la entrada de ninguno ${ }^{25}$.

Obviamente la situación en el castillo se hizo insostenib!e, por lo que el gobernador Coppinger hubo de encargarse de la capitulación en noviembre de 1825 , después de consultar a la junta de guerra. En un oficio posterior al Capitán General se justificó alegando que «el desaparecimiento de

\footnotetext{
AGl., Papeles de Cuba, legajo 2068.

Ibidem.

AGI., Papeles de Cuba, legajo 2115.

AGl., Papeles de Cuba, legajo 2137.

AGI., Papeles de Cuba, legajo 2068.
} 
casi toda la guarnición del castillo de San Juan de Ulúa de su interino mando, causada por la enfermedad escorbútica, falta de viveres para el sostén de la porción de enfermos, entre ellos oficiales y él mismo, corto número de sanos que quedaban, he tenido que capitular el 18 del corriente y en consecuencia evacuar aquel el día de ayer, quedando yo embarcado y en disposición de dar a la vela el día de mañana si el tiempo lo permite, con los tristes restos que presentan en esta plaza de los honrados y sufridos leales españoles que con el bergantín de guerra Victoria, disidente mexicano que convoya a otro mercante inglés, conduciendo los pocos restos de la guarnición».

El Capitán General abrió una investigación por esta capitulación, tomando declaración a varios oficiales destinados en la fortaleza, incluido el mismo Coppinger. Es interesante el testimonio del capitán de artillería Miguel Suárez del Valle, quien alegó que «de su cuerpo había en la guarnición 100 hombres y 30 obreros, del Batallón de Cataluña 300 hombres, mandados por el teniente coronel don Ignacio Castella y 12 oficiales, de las milicias pardas y morenos 102 hombres mandados por el ayudante don José María Estenoz, además de 50 ó 60 marineros, 80 presidiarios y 15 empleados de la Real Hacienda. En agosto comenzó el escorbuto y disminuyó enormemente la fuerza y hubo que disminuir la fuerza del servicio, además que aumentaba el cerco de los disidentes por el mar. En la fortaleza hubo un total de bajas entre muertos, apestados y prisioneros de 380 y más de 280 eran de tropa, y casi todo a partir de julio, pues todo empezó con el contagio. Los últimos víveres llegaron en marzo y eran vino tinto, aguardiente, pasas, algunas frutas, como plátanos y boniatos desde La Habana; desde Nueva Orleáns el mismo día vinieron jamones, gallinas, vino, papas, dulces, frutas y harina, que se repartió entre la guarnición. No entraron más víveres hasta el día de la capitulación». Por su parte, el médico declaró que "desde julio hasta el 18 de noviembre hubo 341 muertos de escorbuto y había en esa fecha 166 enfermos. Sólo quedaban sanos 1 jefe, 12 oficiales y 89 de tropa y no totalmente sanos, y además los víveres se habían corrompido" ${ }^{26}$.

El Capitán General no encontró responsabilidad en Coppinger y consideró justa su decisión. De esta forma penosa, pero heroica, terminó la presencia española en Costa Firme.

A lo largo de este trabajo se han podido ir siguiendo los pasos de la expedición que, formada por fuerzas militares españolas peninsulares,

26 AGl., Papeles de Cuba, legajo $2137 \mathrm{~b}$. 
partió hacia las tierras americanas en la segunda década del siglo XIX con la intención de recuperar para la Corona las provincias americanas que se habian emancipado, en este caso concreto la de Nueva España. La misión, a priori, no se consideraba muy difícil, ya que era el enfrentamiento de un ejército regular dotado de una amplia experiencia militar obtenida en la recién terminada guerra contra Francia con unas tropas mal organizadas y peor disciplinadas, aunque eso sí, bastante más numerosas. Pero el lugar de la acción estaba muy lejos de Europa y las tropas peninsulares no estaban aclimatadas a aquellas tierras, además de que la hacienda española no estaba para grandes aventuras.

El resultado no podía ser otro que el ya sabido, pues aunque el grado de disciplina y subordinación de las tropas y de los oficiales, además de su capacidad de sufrimiento, fueron admirables, la falta de fuerzas para conseguir una defensa efectiva de Veracruz primero, y después la inexistencia de una marina de guerra que mantuviera abierta la vía de enlace con Cuba para permitir el relevo y abastecimiento de las tropas, provocaron que las enfermedades, sobre todo el escorbuto, se cebaran entre los defensores del castillo. A su gobernador Coppinger no le quedó otra salida en noviembre de 1825 que la capitulación, después de resistir cuatro años de asedio y con una fuerza útil casi inexistente, no sin antes escribir una brillante página de comportamiento militar que suscitó la admiración de los contemporáneos. 